\title{
Psychological aspects of formation of ecologically relevant behavior of students of the faculty of agriculture
}

\author{
Elena Azarko ${ }^{1, *}$, Igor Kupriyanov ${ }^{1}$ \\ ${ }^{1}$ Don State Technical University, 1, Gagarin sq., 344003, Rostov on Don, Russia
}

\begin{abstract}
The article provides an analysis of studies showing the need for a psychological approach of meaning building and meaning regulation in the formation of an integral worldview, environmental values and environmentally relevant behavior of agriculture students. In conclusion, recommendations with suggestions on the use of theoretical foundations and methodological techniques of meaning for teaching students of the agricultural sector are presented.
\end{abstract}

\section{Introduction}

Currently, the Russian system of training for the agro-industrial complex is undergoing modernization related to increasing the availability of education for rural youth, as well as the training of qualified personnel capable of ensuring the efficient management of the agro-industrial complex and being competitive in the labor market. The modern education system allows us to form the horizons and ecological worldview of the graduate, covering the entire system of network relations between the various components of the agricultural sector [16,27].

The psychological aspects of education, providing a new type of motivation and initiaing students to obtain general cultural and professional competencies, are the mechanisms of meaning formation $[1,20,21,25,26]$.

At all times, human life is associated with its interaction with nature through labor. The organization and quality of life depend on the goals and nature of human labor. If a period is characterized by ecological disadvantage, then its basis should be sought in technologically oriented work, in its purposes for the consumptive use of the nature, when its ecological settings and content are not taken into account [5]. The obvious conclusion about the need to rethink the values of a person and the nature of his work suggests itself.

\section{Scope and objectives}

The goal of this work is to form a common understanding of the use of elements of the meaning-forming approach when teaching students of agricultural specialties environmentally relevant behavior.

\footnotetext{
*Corresponding author: azarkoem@yandex.ru
} 


\section{Methods}

The main method was the analysis of theoretical and applied research in the field of ecological worldview, consciousness, values and environmentally relevant behavior.

\section{Analysis of publications. Environmental awareness, worldview, values, environmental culture}

Ecologically relevant behavior is studied in the context of an ecological worldview, consciousness, meanings, values, as well as ecological culture and the subjective quality of life associated with them $[5,7,10,13,18,19,21,25]$. At the same time, questions of the historical, legal, religious and moral formation of the ecological worldview, changes in the anthropocentric paradigm of environmental consciousness to ecocentric are relevant $[3,4$, $5,9,17,22,26]$.

The term "worldview" derived from "viewing the world" has undergone a change and is filled with new meaning in the context of an "ecological worldview". It is understood as awareness of the priority of ecocentrism over anthropocentrism, it means responsibility for the survival of the planet and for the fate of the entire socio-natural system. It assumes an adequate reflection of the connection, unity and difference of society and nature as components of a socio-ecological system [3].

Worldview and consciousness are interconnected. In line with philosophical thought, the characterization of environmental consciousness is associated with the understanding of the essence of such phenomena as the ideal of human beauty and nature, the living through and acceptance of the value of living spirited nature, the cocurrence of the rhythms of nature and man, and understanding of environmental catastrophe [11, 14]. Environmental consciousness is one of the manifestations of human consciousness, focused on the living space of man, directing his life to preserve this space in the state of environmental stability, improve its environmental situation and prevent the environmental crisis [4, 12, 14,19]. M. Sanchez addresses 4 aspects of environmental consciousness: general beliefs / values (affective aspect); personal attitudes (dispositional aspect); pro-environmental behavior (active aspect); information / knowledge (cognitive aspect) [4].

Two types of environmental consciousness are discussed - anthropocentric and ecocentric $[4,5,14,15]$. The anthropocentric type of environmental consciousness is a system of ideas about the world, including “... 1) the opposition of man as the highest value and nature as his property; 2) the perception of nature as an object of unilateral human impact; 3 ) the pragmatic nature of the motives and goals of interacting with it ... "[cit. 5, p. $10]$. For the ecocentric type of environmental consciousness, “... 1) focus on environmental expediency, the lack of contrast between man and nature; 2) the perception of natural objects as full-fledged entities, partners for interaction with humans; 3) the balance of pragmatic and non-pragmatic interaction with nature ... " are typical [cit. 5, p. 13].

The environmental approach has influenced and is affecting many aspects of life. With the development of industry in the 70 s and the subsequent technogenization of society, the issues of conservation of natural resources attracted more and more attention of the public, the economics and the legal regulation $[9,11,15,16,17]$. The environmental values are declared: Man as a part of Nature, Habitat, Biosphere; The beauty of nature and man, Empathy-Concern-Responsibility, Sacred nature, Harmony-Balance $[4,5,10]$. In this case, the values of a person are a priori understood as internal fundamental mechanisms of man, regulating and directing his activity in relation to nature, assessing alternatives to possible developments, understanding risks and responsibility for consequences $[13,15,16,17]$. 
Ecologically relevant individual behavior is revealed in the context of the dynamic system "society - ecological behavior", which determines the methods of obtaining and using environmental resources by a subject [7].

\section{The main findings and its discussion. Environmentally relevant behavior}

On the problem of environmentally significant behavior, the most developed terminology is the one by I.V. Kryash. She formulated the concept of environmentally relevant behavior as a subject's action to obtain and use an environmental resource. At the same time, the content is considered in two ways: 1) through its objective contribution to the processes of anthropogenic impact on ecological systems and 2) through subjective ideas about the environmental significance of the actions taken. It is stated that studies of environmentally relevant behavior are carried out in the context of opposing the eco-destructive and environmentally friendly modes of action. The focus is on the eco-friendly / proenvironmental behavior [5].

It is shown that a wide range of beliefs as social attitudes is included in its regulation of the internal determinants of eco-saving behavior:

-worldview ecological mindsets (Danlop R., Kilborn V., Stern P., E.V. Rudomino Dusyatskaya),

-mindsets in relation to nature (Bamberg S., Deryabo S.D., Kals E., Meyer S., T. Naito, Nisbet E., Schulz W.),

-mindsets in relation to the problem of anthropogenic environmental changes (Barton M., Oscamp S., Thompson S., Sevillano V. and others),

-social attitudes: economic, religious, political (Blackie N., Dunlop R., G. Tunzer),

-personal values (Ditz T., Stern P., Heidmets M. Schulz W.) [7].

To designate a systemic dispositional education that supports the proecological orientation of the subject's behavior, the category of environmental concern is used in the psychology of environmental conservation. The emotional basis of environmental concern is the experience of commonness with the natural environment, which determines the ecological identity of the individual [6]. The experience of personal involvement in the problem of environmental conservation, and then the understanding of this relationship, manifests itself in the activation of a proecological norm, environmental responsibility ( $\mathrm{T}$. Volk, H. Hungerford), settings for eco-saving opportunities [4, 5, 7].

At the same time, in psychology, D. A. Leont'ev presents a whole complex of interconnected components of semantic structures - values, personal meaning, semantic construct, semantic attitude, semantic disposition, semantic education. The semantic regulation is the leading level of mental regulation of the life of the subject [8].

With the systematization of studies on environmentally relevant behavior and semantic regulation, the following table 1 can be presented below.

Table 1. The components of interconnected semantic structures in the context of environmentally relevant behavior.

\begin{tabular}{|c|l|c|}
\hline $\begin{array}{c}\text { Components of } \\
\text { semantic structures } \\
\text { (according to D.A. } \\
\text { Leontiev) [8] }\end{array}$ & Components of the environmentally relevant behavior & Authors \\
\hline Personal value & $\begin{array}{l}\text {-ecological values: human-life-harmony } \\
\text {-values: "Environmental safety (environmental stability, } \\
\text { confidence in the quality of air, water, housing)" } \\
\text {-personal values: "Openness to change (wisdom, unity with } \\
\text { nature, experience of beauty, creativity, inner harmony, }\end{array}$ & $7,20,23$ \\
\hline
\end{tabular}




\begin{tabular}{|c|c|c|}
\hline & $\begin{array}{l}\text { spiritual life)" } \\
\text {-biosphere values (unity with nature, involvement in the } \\
\text { environmental community) } \\
\text {-values of social harmony (as the need for cohabitation) }\end{array}$ & $\begin{array}{r}5,6,10 \\
5,15,16 \\
\end{array}$ \\
\hline Motive & $\begin{array}{l}\text {-motive of destruction-creation } \\
\text {-environmental intentions } \\
\text {-motive of authority as appropriation of environmental } \\
\text { resources }\end{array}$ & 19 \\
\hline Semantic construct & -ecological worldview mindsets & $\begin{array}{l}4,6,7 \\
11,23\end{array}$ \\
\hline Semantic disposition & -environmental concern & $4,9,23$ \\
\hline Semantic mindset & $\begin{array}{l}\text {-mindsets in relation to nature } \\
\text { - social mindsets: economic, religious, political } \\
\text {-mindsets in relation to the problem of anthropogenic } \\
\text { environmental changes }\end{array}$ & $5,7,10$ \\
\hline Personal sense & $\begin{array}{l}\text {-experience of commonness with the natural environment, } \\
\text { determining the ecological identity of the individual } \\
\text { - personal involvement in the problem of environmental } \\
\text { conservation, } \\
\text { - personal environmental responsibility }\end{array}$ & $\begin{array}{l}7,9,10 \\
17,23\end{array}$ \\
\hline $\begin{array}{l}\text { Empirically Recorded } \\
\text { Effects }\end{array}$ & $\begin{array}{l}\text {-Activity direction } \\
\text { - The integral space of "quality of life" }\end{array}$ & $7,15,20$ \\
\hline
\end{tabular}

Commenting on the table, it can be stated that the environmentally relevant behavior is formed by environmental values, motives of destruction-creation, environmental intentions, ecological worldviews, personal involvement in the problem of environmental conservation, personal environmental responsibility, as well as the focus of actions.

Semantic formations form stable patterns of organization - personal dynamic semantic systems (D.A. Leontiev), manifested in the direction of the subject's activity and revealing his internal position (L. I. Bozhovich, V. A. Yadov) [8]. The internal position characterizes the system of semantic formations of a person, refracts cultural, socialized meanings, and is realized in the subjective activity of a person.

It is suggested by I.V. Kryash to consider the ecological position as the controlling parameter of the system of semantic regulation of ecologically relevant behavior - the position taken by a person in relation to the ecological environment in the light of life support problems [7]. The ecological position determines the semantic dynamics of environmentally relevant behavior, ensuring the subject's selective attitude to cultural meanings, and manifests itself in an environmentally friendly or eco-destructive orientation of actions. This orientation is supported by certain ways of understanding environmental reality, fixed in the form of semantic formations of the personality, in the first place individual values, semantic constructs and semantic dispositions.

When describing the environmentally relevant behavior according to I.V. Kryash the following characteristics are formed.

\section{Eco-Destructive Relevant Behavior}

-by the direction of action - the growth of material consumption (consumption of environmental resources);

- by the endorsed social paradigm - the dominant social paradigm;

-by the main source of life sustenance (in the views of the subject) - financial and economic system (money);

- by the sence-creating context in which the environmentally relevant behavior is assessed the financial and economic context (interaction with the social environment); 
- by identity - the economic identity (the experience of being involved in goods-money relations);

- by the value meanings of the ecological environment - monetary-utilitarian (goodsmonetary);

- by the leading criterion of quality of life - financial well-being [7].

\section{Eco-friendly relevant behavior}

-by the direction of action - maintaining environmental sustainability, reducing anthropogenic pressure on the biosphere;

-by the endorsed social paradigm - the new environmental paradigm;

- by the main source of life sustenance (in the views of the subject) - ecological systems (biosphere);

- by the sence-creating context in which the environmentally relevant behavior is assessed ecological (interaction with the ecological environment);

- by identity - environmental (experiencing one's community with the biosphere);

-by the value meanings of the ecological environment - biosphere (the basis of life);

- by the leading criterion of quality of life - environmental well-being [7].

The analysis of the psycho-diagnostic tools used for research in the context of the topic of interest to us shows that the following are used to study the value-semantic sphere: tests "Value Questionnaire" by S. Schwartz, "Value Orientations" by M. Rokich, "Life-Purpose Orientations" by D.A. Leontiev, the methods "Morphological test of life values" by I.G. Senina and "The Study of Environmental Orientations" by T.V. Ivanova [1, 2, 7].

To study the environmental motivational-semantic components, formations and attitudes, the following tests are used: the test "Diagnosis of the degree of subjectivity of the perception of natural objects" by S.D. Deryabo, the test "Alternative" by S.D. Deryabo and V.A. Yasvin, the associative test "EZOP (Emotions -Knowledge-Protection-Benefit)" by S.D. Deryabo and V.A. Yasvin, the test-scale " The New Ecological Paradigm "(NEP) by R. Dunlap and D. vanLear, the inventory "Attitude to the environment" by A.M .Levochkina, the inventory "Eco-44" by I.V. Kryazh, the test "Scale of anthropocentric and ecological attitudes" by S. Thompson and M. Barton, the self-report questionnaire on proecological behavior by P. Casey and C. Scott, the test "Scale of environmental concern" by M. Ojal, the test-scale "The Inclusion of nature in the I ") by W. Schulz [4, 5, 7, 18, 24].

In the research of I.V. Kryazh it is shown that the ecological position is associated with the lifestyle of the subject, with the assessment of quality of life and values. The most significant differences were identified for four criteria of quality of life: human actions (it reflects the internal position in understanding the quality of life), health, nature, freedom. All the differences found are related to the economic situation in a country. A sharp deterioration in the economic situation in a country leads to the weakening of the external position of the individual and to the aggravation of anxiety about one's health as a condition for a quality life. In a stable economic situation, older respondents more often than younger ones turn to nature as a condition for a quality life, but this difference is leveled after the aggravation of the economic situation [6]. Communication with nature and the ability to live in an environmentally friendly environment is endowed with meanings of inner harmony. The significance of nature as a criterion for the quality of life and as value was determined by the tasks of revealing an internal (spiritual) resource [6].

The authors agree that the process of the development of environmental values and related environmentally relevant behavior is the interconnected activity of a teacher and a student $[1,10]$. In the formation of environmental values and the relevant behavior of students, the following is important 
1) the adoption of environmental material that has a personal meaning for the future life and profession of a student;

2) focus on a collective search for a way to solve an environmental problem;

3) the need for their own attempts to interpret natural or social phenomena;

4) a clear personal worldview on environmental problems and how to solve them;

5) the ability to defend one's opinion based on environmental values in combination with environmental knowledge and ethical standards. At the same time, teaching activities are characterized by:

1) the ability of a teacher to dialogue - in the subject-subject communication to stimulate an emotional-value attitude to nature, ecology and the awakening of eco-friendly behavior;

2) knowledge of techniques and methods for including and transmitting the environmental values in the educational process;

3 ) the presence of the system of environmental values in the hierarchy of personal values ;

4) the ability to set the direction in choosing a system of professional values, meanings and worldview positions through the taught discipline;

5) the ability to apply elements of a communicative-dialogical, imitation-game, taskcontextual and design approach in training $[1,10,22]$.

\section{Conclusions and perspectives}

As a conclusion, we may say that the changing society, the modern information space, and economy challenge the world of professions, the educational environment, and man. Serious environmental problems threaten with no less serious environmental consequences in the absence of adequate actions of professional people and society. The main expectation of nature is the moral responsibility for the content of education and profession, for the spiritual fulfillment of a man in his attitude to nature [5]. The assessment of the results of this relationship and the organization of its conditions are important. In the field of education today, one should think about rethinking, supplementing its content, taking into account the coordination of natural processes and society trends. The modern profession is not an activity that focuses solely on the economy, but the activity that promotes social and environmental sustainability. Education and profession today are environmental values [5, $22,24]$.

1. The formation of the ecological worldview, consciousness and values as a substantial part of general cultural competencies is the object of close attention of the economics, politics, science, and legal norms.

2. Environmental awareness is determined by beliefs / values (affective aspect); personal attitudes (dispositional aspect); pro-environmental behavior (active aspect); information / knowledge (cognitive aspect).

3. Eco-friendly relevant behavior is the opposite of eco-destructive behavior; contributes to maintaining environmental sustainability, reducing anthropogenic pressure on the biosphere; affects the sense-creating context, the experience of one's commonness with the biosphere, personal environmental responsibility; forms personal involvement in the problem of environmental conservation and environmental well-being.

4. For the organization of research projects to study the specifics of the formation of the students' components of semantic regulation, environmental values, motives, philosophical attitudes, a list of psychodiagnostic techniques has been compiled.

5. In the formation of environmental values and environmentally relevant behavior in the educational process, it is possible to use methodological techniques of sense creation technology. 


\section{Recommendations}

1. In our opinion, it is possible to carry out a study of the formation of environmental consciousness in preparation of personnel for the agricultural sector, as well as the environmentally relevant behavior of students of an agricultural department, in form of joint research projects between departments.

2. A perspective in the educational process of training of personnel of the agro-industrial complex may be

- the use of diagnostic techniques to study the dynamics of the ecological position of students, as well as the structure of their value-motivational sphere, at different stages of training;

- the inclusion in the practice of teaching the disciplines of the social attitudes of environmental conservation, value meanings of the biosphere and environmental wellbeing;

- the formation of the environmental responsibility;

- the development of the eco-friendly relevant behavior.

\section{References}

1. I.V. Abakumova, Learning and meaning: sense creatiom in the educational process (RSU, Rostov-on-Don, 2003)

2. I.V. Abakumova, E.M. Azarko, Diagnostics of individual characteristics of the semantic sphere of a student's personality (Rostov-on-Don, 2001)

3. V.V. Bushueva, N.N. Bushuev, Ecological worldview and its features 10(96), 73-76 (2018) ISSN 2618-9690, www.gramota.net/materials/9/2018/10/

4. V.N. Demenshin, World Science Journal 5, 5 (2017) https://mirnauki.com/PDF/18PSMN517.pdf

5. S.D. Deryabo, V.A. Yasvin, Environmental pedagogy and psychology (Phoenix, Rostov-on-Don, 1996)

6. S.K. Gural, G.I. Petrova, O.S. Golovko, Bulletin of PNIPU. Problems of linguistics and pedagogy 3, 127-138 (2018)

7. I.V. Kryazh, The psychology of semantic regulation of environmentally relevant behavior (Kharkov, 2013)

8. D.A. Leontiev, The psychology of sense (Sense, Moscow, 2019)

9. Yu.V. Maslova, Humanities of the South of Russia 8(38), 178-188 (2019)

10. I.V. Meshcheryakova, Proceedings of Penza State University. Natural Sciences 20, 310-316 (2012)

11. K.S. Romanova, Ecological worldview and its legal aspect, 97-111 (2011)

12. T.F. Stolyarova, History and modernity 2, 131-143 (2005)

13. Yu.L. Tkachenko, M.V. Komissarova, I.S. Scherbakova, Society: philosophy, history, culture 4 (2018)

14. A.I. Toboev, Bulletin of Omsk University. Economic and social sciences, 286-291 (2016)

15. Z.N. Khabibullina, Environmental consciousness: a change in regulations. Manuscript 1(63) (2016)

16. A.V. Khodchenkov, The ecological culture of Russian youth: state and trends of transformation: Abstract of. diss. (Rostov-on-D., 2006) 
17. M.A. Shved, Society: philosophy, history, culture 1 (2018)

18. S.D. Clayton, The Oxford Handbook of Environmental and Conservation Psychology (OUP USA, 2012) https://books.google.ru/books?id=kKovr_MBnUC\&pg=PA142\&lpg=PA142\&dq=env ironmentally+relevant+behavior\&source=bl\&ots=9_uYvIrpgb\&sig=ACfU3U0a3QQV OGgERNy2frNX6EqOJ04Gw\&hl=ru\&sa=X\&ved=2 $\mathrm{ahUKEwiq2ef1087oAhWJ6aYK}$ HROZAuYQ6AEwCXoECAsQNQ\#v=onepage\&q=environmentally\%20relevant $\% 20 \mathrm{~b}$ ehavior\& $\mathrm{f}=$ false

19. E.M. Markowitz, B.F. Malle, Ecopsychology 4(1) Doi: https://doi.org/10.1089/eco.2011.0044

20. Journal of Environmental Psychology 19(3), 277-286 (1999) https://doi.org/10.1006/jevp.1999.0134https://www.sciencedirect.com/science/article/a bs/pii/S0272494499901342

21. T.E. Parece, T. Younos, L. Grossman, E. Geller, International Journal of Sustainability in Higher Education 14(4), 466-481 (2013) https://doi.org/10.1108/IJSHE-01-20120008

22. W. Newsome, M. Alavosius, Behavior and Social Issues (2011) DOI: $10.5210 /$ bsi.v20i0.3234

23. A.M. Martín, B. Hernández, M. Frías-Armenta, S. Hess, Legal and Criminological Psychology (2012) DOI: 10.1111/j.2044-8333.2012.02062.x

24. E.J. Milner-Gulland, Philosophical Transactions Biological Sciences, 270-278 (2012) DOI: 10.1098/rstb.2011.0175

25. E.S.W. Chan, A.H.Y. Hon, W. Chan, F. Okumus, International Journal of Hospitality Management, 20-28 (2014) DOI: 10.1016/j.ijhm.2014.03.001

26. C.C. Manoli, Studies in Educational Evaluation, 29-37 (2014) https://libgen.is/scimag/10.1016\%2Fj.stueduc.2013.09.008

27. M. Adams, Palgrave Macmillan UK, 279-287 (2016) DOI: 10.1057/978-1-137-351609 